\title{
Schwannoma of the seminal vesicle in a patient with rectal cancer
}

\author{
J ared R. Funston ${ }^{1}$, Charles Le Vea ${ }^{2}$, Ashwani Rajput ${ }^{3}$ \\ 1. University of New Mexico School of Medicine, Albuquerque, NM, USA. 2. Department of Pathology, Surgical Pathology, \\ Roswell Park Cancer Institute, Buffalo, NY, USA. 3. Department of Surgery, Division of Surgical Oncology, University of \\ New Mexico, Albuquerque, NM, USA.
}

Correspondence: Ashwani Rajput. Address: Department of Surgery, Division of Surgical Oncology, University of New Mexico, Albuquerque, NM, USA. E-mail: arajput@salud.unm.edu

Received: August 23, 2014

DOI : $10.5430 / c r c p . v 2 n 2 p 62$
Accepted: December 2, $2014 \quad$ Online Published: January 16, 2015

URL: http://dx.doi.org/10.5430/crcp.v2n2p62

\section{Abstract}

Introduction: Schwannomas are benign tumors arising from the cells responsible for producing the myelin sheath surrounding peripheral nerve cells.

Presentation of case: A patient presented with intermittent bloody stools and diarrhea. Following a work-up, including colonoscopy, computed tomography (CT) scan, and endorectal ultrasound and biopsy, he was found to have a clinical T3N1 rectal adenocarcinoma. The CT scan also showed an incidental mass in the right seminal vesicle that on biopsy was consistent with a benign stromal nodule. After neoadjuvant chemoradiation, a low anterior resection (LAR) and concomitant resection of the right seminal vesicle was performed. Pathologic evaluation of the right seminal vesicle revealed a benign schwannoma.

Discussion: This unusual case of a solitary schwannoma of the seminal vesicle in a patient with a locally advanced rectal adenocarcinoma illustrates the difficulty in diagnosing these rare lesions because of their generally asymptomatic nature.

\section{Key words}

Schwannoma, Seminal vesicle, Neurilemmoma, Rectal cancer

\section{I ntroduction}

Schwannomas, or neurilemmomas, are benign tumors arising from Schwann cells. These cells are responsible for formation of the myelin sheath of peripheral nerve cells. As such, they may arise anywhere along the course of peripheral nerves. Diagnosis commonly follows symptomatic compression of nerves adjacent structures by mass effect, or by incidental finding during workup for another condition. We report an unusual case of solitary schwannoma of the seminal vesicle in a patient with a locally advanced rectal adenocarcinoma.

\section{Case presentation}

A 63-year-old Caucasian male presented with complaints of diarrhea and intermittent blood in is stool for several months. He denied any weight loss, anorexia, abdominal pain, dysuria or hematuria. He had no other constitutional symptoms. His 
history was significant only for a 40 pack-year history of smoking, which he had stopped 30 years prior to this episode. On physical examination, he had hemoccult positive stool on digital rectal exam. Colonoscopy revealed a circumferential fungating mass $8 \mathrm{~cm}$ from the anal verge approximately $6 \mathrm{~cm}$ in length. Pathologic review of biopsies demonstrated a moderately differentiated rectal adenocarcinoma. Endorectal ultrasound showed it to be a T3N1 lesion. Initial carcinoembryonic antigen (CEA) was 21.2 units/ml. Staging computed tomography (CT) scan showed no evidence of metastatic disease, but did reveal a $5.0 \mathrm{~cm} \times 4.5 \mathrm{~cm}$ mass in the right seminal vesicle with no evidence of extension into the surrounding tissue. Prior to beginning neoadjuvant chemoradiation, a CT guided core needle biopsy of the seminal vesicle lesion was performed and revealed a benign stromal nodule. In light of his clinical stage IIIB disease, he proceeded with neoadjuvant radiation to a total of 50.4 Gy with concurrent 5-FU based chemotherapy. Restaging CT scan at the conclusion of neoadjuvant treatment again showed no signs of metastatic disease, but a persistent right seminal vesicle mass with not change in size. His CEA at this time had decreased to 3.2 units $/ \mathrm{ml}$.

Twelve weeks after the completion of his neoadjuvant therapy, a low anterior resection (LAR) with concurrent right seminal vesicle resection was performed. The right seminal vesicle was noted to be firm and fixed, but well encapsulated. Pathologic examination of the specimens revealed a T3N1 moderately differentiated adenocarcinoma of the rectum, and a schwannoma of the seminal vesicle, measuring $4.7 \mathrm{~cm} \times 4.0 \mathrm{~cm} \times 3.5 \mathrm{~cm}$. It was attached to an atrophic seminal vesicle. It was light tan on gross examination with a $1 \mathrm{~cm}$ focal area of hemorrhage. Histologic architecture showed vacuolated hypocellular areas with the typical whorled appearance and large myxomatous spaces of an Antoni A growth pattern (see Figure 1, 2). The tissue stained diffusely and strongly for S-100 (see Figure 3). Immunohistochemical stains for muscle markers, muscle specific actin, desmin and caldesmon were negative.

Figure 1. Low power photomicrograph $(40 \times)$ demonstrating a cellular schwannoma containing predominantly Antoni A regions and Verocay bodies.
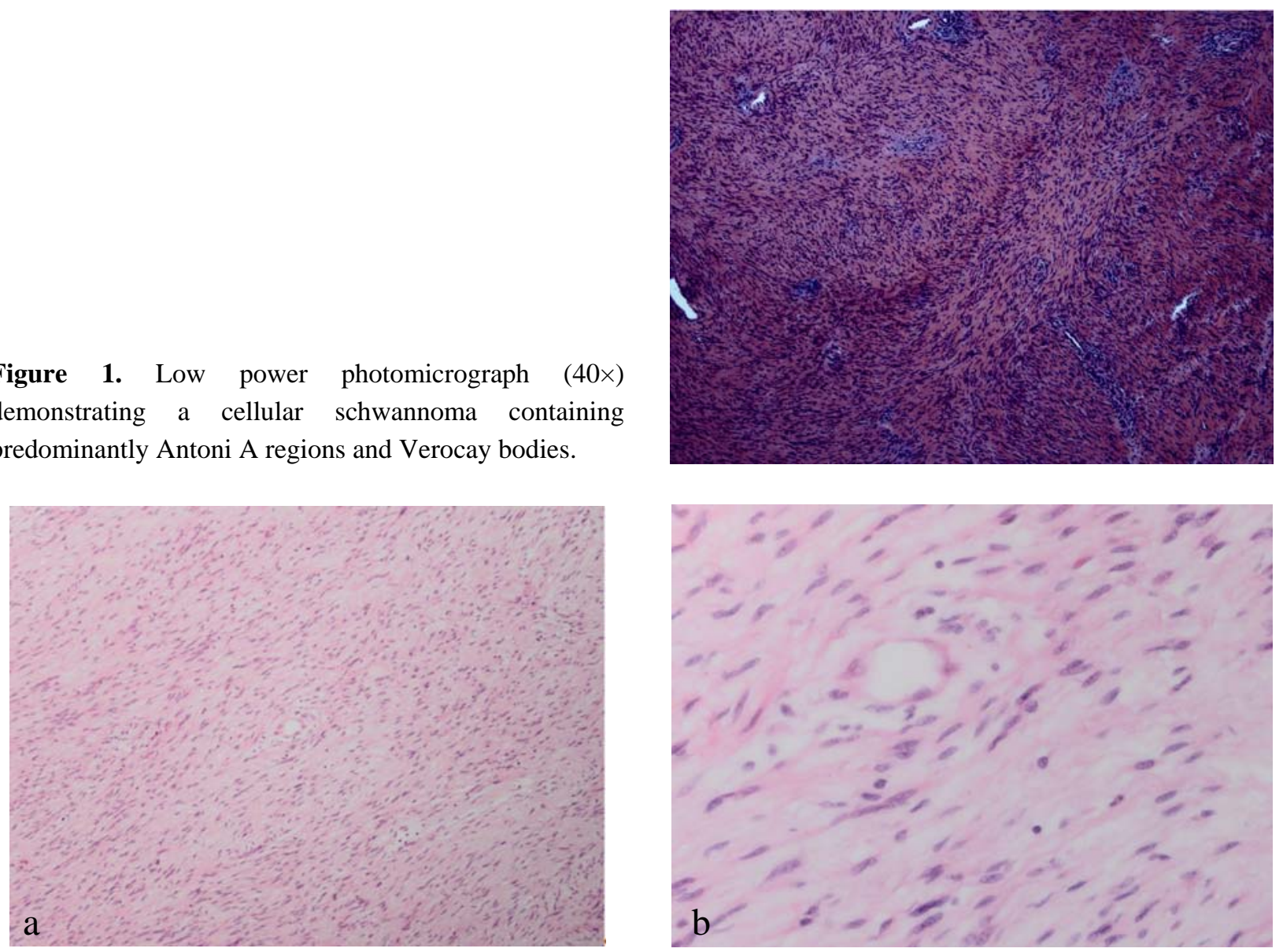

Figure 2. a: This $40 \times$ power H\&E stain demonstrates a cellular schwannoma. It is composed almost exclusively of Antoni A areas and a lack of Verocay bodies. b: This is a $400 \times$ magnification of the cellular schwannoma. 
Figure 3. High power photomicrograph $(400 \times)$ demonstrating a positive S-100 immunohistochemical stain of the schwannoma.

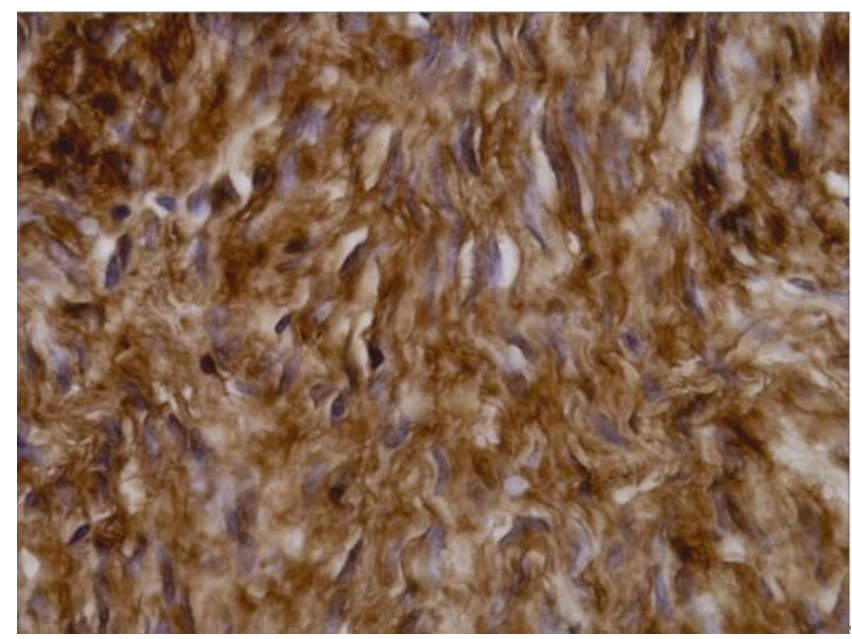

\section{Discussion}

Schwannomas are tumors that are most frequently found in the head, neck, mediastinum, and retroperitoneum (cystic schwannoma). Primary benign tumors of the seminal vesicles are rare and consist of cystadenoma, papillary adenoma, leiomyoma, teratoma, neurilemoma, and epithelial stromal tumor ${ }^{[1]}$. More frequently neoplasms of the seminal vesicle are malignant including adenocarcinoma, leiomyosarcoma, angiosarcoma, carcinoid, seminoma, and cystosarcoma phyllodes ${ }^{[1]}$. Furthermore, few intraabdominal or pelvic neoplasms spread to the seminal vesicles with any regularity. Diagnosis of seminal vesicle neoplasms is hampered by the generally asymptomatic nature of these lesions. Impingement on nearby structures is usually a late occurrence and most symptoms of seminal vesicle neoplasms are nonspecific including hematospermia, hematuria, urinary infection, dysuria, painful defecation, and pelvic pain ${ }^{[2]}$. On digital rectal exam, an enlarged seminal vesicle is usually not palpable. The area above the prostate, however, can be enlarged and compressible if the seminal vesicle is dilated or firm and indurated if the organ contains tumor. These findings would indicate further investigation with trans-rectal ultrasound (TRUS). Fine needle aspiration or core biopsy must be performed to confirm the tissue diagnosis.

Diagnosis of extra-axial schwannomas and other seminal vesicle tumors is greatly aided by the use of imaging. CT will identify tumors in the seminal vesicle and shows schwannomas as lesions that are isodense with adjacent muscle possibly with cystic, hemorrhagic, and or calcific internal features ${ }^{[1,3]}$. Magnetic Resonance Imaging shows schwannomas as hyperintense on T-2 weighted images relative to T-1 images ${ }^{[3,4]}$. The advantage of using magnetic resonance imaging lies in the enhanced depiction of anatomic relationships. Unfortunately, neither of these modalities produces images pathognomic for schwannomas, nor can they distinguish benign from malignant pathology with high degree of certainty ${ }^{[5]}$.

Both grossly and microscopically schwannomas commonly contain areas of hemorrhage and cystic degeneration. Within these tumors two distinct patterns of cell growth may be differentiated histologically: Antoni A and Antoni B ${ }^{\text {[6] }}$. Verocay bodies (hypercellular areas containing spindle shaped cells with palisaded nuclei) are characteristic features of the former while the latter has loose, haphazard arrangements of cells in myxomatous stroma. Further characteristics of Antoni B are large vascular spaces with hyalinized walls. The presence of S-100 protein on immunohistochemical staining is also common with Schwann cells. Although malignant change in these tumors is extremely rare, local recurrence is reportedly associated with incomplete excision ${ }^{[3]}$. Therefore, extra-axial schwannomas should be treated with complete excision whenever possible to minimize the risk of recurrence ${ }^{[7]}$. All reported cases of seminal vesicle schwannoma have been treated with complete surgical resection. 
Solid lesions of the seminal vesicles should be treated with surgical excision via either a transvesical, transperineal, paravesical, retrovesical or transcoccygeal approach. Transperineal approaches are heralded for smaller benign or malignant tumors, while anterior abdominal approaches best handle larger neoplasms ${ }^{[8]}$. In this case, a laparotomy was performed for LAR and therefore, the seminal vesicle schwannoma was removed transabdominally in conjunction with the rectal resection.

Only five reports of seminal vesicle schwannoma exist in the literature and none have been associated with rectal cancer. Two of these were diagnosed during workup for prostate cancer ${ }^{[9-13]}$. This patient's asymptomatic schwannoma probably developed from an adrenergic or cholinergic branch of the hypogastric or pelvic nerve innervating the right seminal vesicle. Because of its benign nature, it is not surprising that it did not respond to neoadjuvant chemoradiation administration to downstage rectal tumor. There is no known or published association between rectal cancers and schwannomas of the seminal vesicle. The current report is the first, to our knowledge, diagnosing a schwannoma during workup and treatment of a gastrointestinal malignancy.

\section{References}

[1] Kim B, Kawashima A, Ryu JA, Takahashi N, Hartman RP, King BF. Imaging of the seminal vesicle and vas deferens. Radiographics. 2009; 29(4): 1105-21. PMid: 19605659. http://dx.doi.org/10.1148/rg.294085235

[2] Campobasso D, Fornia S, Ferretti S, Maestroni U, Cortellini P. Primary bilateral seminal vesicle carcinoma: description of a case and literature review. Int J Surg Pathol. 2012; 20(6): 633-5. PMid: 22723505. http://dx.doi.org/10.1177/1066896912450314

[3] Okuyama T, Tagaya N, Saito K, Takahashi S, Shibusawa H, Oya M. Laparoscopic resection of a retroperitoneal pelvic schwannoma. J Surg Case Rep. 2014; 2014(1). PMid: 24876325.

[4] Strollo DC, Rosado-de-christenson ML, Jett JR. Primary mediastinal tumors: part II. Tumors of the middle and posterior mediastinum. Chest. 1997; 112(5): 1344-57. PMid: 9367479. http://dx.doi.org/10.1378/chest.112.5.1344

[5] Khanlou H, Khanlou N, Eiger G. Schwannoma of posterior mediastinum: a case report and concise review. Heart Lung. 1998; 27(5): 344-7. http://dx.doi.org/10.1016/S0147-9563(98)90055-3

[6] Anthony DC, Voge FS. Peripheral nervous system. In: Damjanov I, Linder J, eds. Anderson’s Pathology. 10th ed. St Louis, MO: Mosby-Year Book; 1996.

[7] Kagaya H, Abe E, Sato K, Shimada Y, Kimura A. Giant cauda equina schwannoma. A case report. Spine. 2000; 25(2): $268-72$. PMid: 10685494. http://dx.doi.org/10.1097/00007632-200001150-00021

[8] Sandlow JI, Winfield HN, Goldstein M. Surgery of the scrotum and seminal vesicles. In Alan J. Wein (Ed). Campbell-Walsh Urology. Philadelphia, PA: Saunders Elsevier. 2007; 1098-1127.

[9] Iqbal N, Zins J, Klienman GW. Schwannoma of the seminal vesicle. Conn Med. 2002; 66(5): 259-60. PMid: 12071106.

[10] Latchamsetty KC, Elterman L, Coogan CL. Schwannoma of a seminal vesicle. Urology. 2002; 60(3): 515. http://dx.doi.org/10.1016/S0090-4295(02)01815-0

[11] Han P, Wei Q, Yang YR. Neurilemmoma of a seminal vesicle. Chin Med J. 2007; 120(15): 1383-4.

[12] Furtado AM, Carrasquinho E, Ferreira M, Afonso A, Ferrito F. Schwannoma, a rare tumor of the seminal vesicle. Cent European J Urol. 2011; 64(1): 44-6. PMid: 24578861. http://dx.doi.org/10.5173/ceju.2011.01.art10

[13] He R, Yang X, Li X, He Z, Zhou L. Cystic schwannoma of a seminal vesicle. J Androl. 2012; 33(5): 798-800. PMid: 22362077. http://dx.doi.org/10.2164/jandrol.111.015917 